\title{
Supporting Information for: Cation Disorder and Lithium Insertion Mechanism of Wadsley-Roth Crystallographic Shear Phases from First Principles
}

\author{
Can P. Koçer ${ }^{\dagger}$, Kent J. Griffith ${ }^{\dagger}$, Clare P. Grey ${ }^{\llbracket}$, Andrew J. Morris ${ }^{\S, *}$ \\ ${ }^{\dagger}$ TCM Group, Cavendish Laboratory, University of Cambridge, J. J. Thomson Avenue, Cambridge CB3 OHE, U.K. \\ ${ }^{\ddagger}$ Department of Materials Science and Engineering, Northwestern University, Evanston, Illinois, 60208, USA \\ "Department of Chemistry, University of Cambridge, Lensfield Road, Cambridge CB2 1EW, U.K.

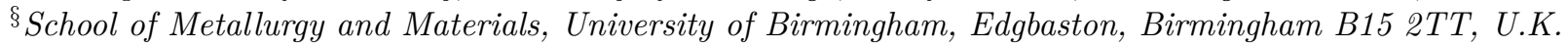

*Email: a.j.morris.1@bham.ac.uk

\section{Tables}

$\mathrm{S} 1 \quad$ Pseudopotential specifications . . . . . . . . . . . . . . . . . . . . S2

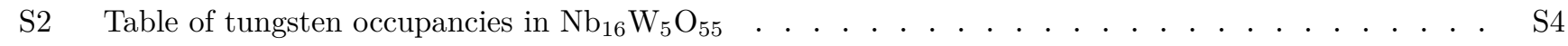

S3 Lithium site energies . . . . . . . . . . . . . . . . . . . . . . . . S7

\section{Figures}

$\mathrm{S} 1 \quad \mathrm{Nb}_{14} \mathrm{~W}_{3} \mathrm{O}_{44}$ tungsten site occupancies as a function of temperature . . . . . . . . . . . . S3

$\mathrm{S} 2 \quad \mathrm{Nb}_{16} \mathrm{~W}_{5} \mathrm{O}_{55}$ tungsten site occupancies as a function of temperature . . . . . . . . . . . . . S3

S3 Lowest energy cation configurations of $\mathrm{Nb} / \mathrm{W}$ oxides . . . . . . . . . . . . . . . . . . . S4

$\mathrm{S} 4 \quad \mathrm{Nb}_{16} \mathrm{~W}_{5} \mathrm{O}_{55}$ structural variability . . . . . . . . . . . . . . . . . . . . . S S

$\mathrm{S} 5 \quad \mathrm{Li}_{x} \mathrm{Nb}_{12} \mathrm{WO}_{33}$ convex hull . . . . . . . . . . . . . . . . . . . . . . S S

$\mathrm{S} 6 \quad \mathrm{Li}_{x} \mathrm{Nb}_{12} \mathrm{WO}_{33}$ adjusted voltage profile . . . . . . . . . . . . . . . . . . S5

$\mathrm{S} 7 \quad \mathrm{Li}_{x} \mathrm{Nb}_{12} \mathrm{WO}_{33}$ lattice evolution including metastable structures . . . . . . . . . . . . . . . S6

S8 Lithium site labelling in $\mathrm{Nb}_{14} \mathrm{~W}_{3} \mathrm{O}_{44}, \mathrm{Nb}_{16} \mathrm{~W}_{5} \mathrm{O}_{55} \ldots \ldots \ldots \ldots \ldots \ldots \ldots$. . . . . . . . . . . . . . 6

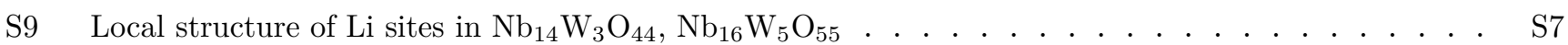

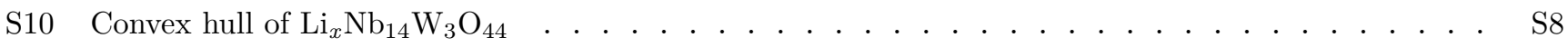

$\mathrm{S} 11 \quad \mathrm{Li}_{x} \mathrm{Nb}_{14} \mathrm{~W}_{3} \mathrm{O}_{44}$ lattice evolution including metastable structures . . . . . . . . . . . . . . S8

$\mathrm{S} 12 \quad$ Electronic structure of $\mathrm{Nb}_{12} \mathrm{WO}_{33}$ and $\mathrm{Nb}_{16} \mathrm{~W}_{5} \mathrm{O}_{55} \quad \ldots \ldots \ldots \ldots \ldots \ldots$. . . . . . . . . . . . S9

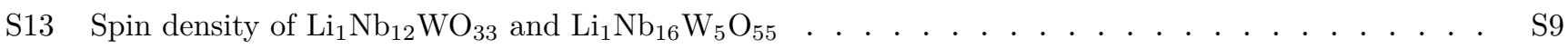

S14 Electronic structure of $\mathrm{Li}_{13} \mathrm{Nb}_{12} \mathrm{WO}_{33}$ and $\mathrm{Li}_{21} \mathrm{Nb}_{16} \mathrm{~W}_{5} \mathrm{O}_{55} \ldots \ldots \ldots \ldots$. . . . . . . . . . . S10

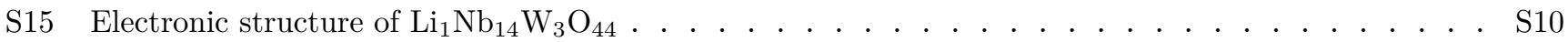

$\mathrm{S} 16 \quad$ Electronic structure of $\mathrm{Li}_{16} \mathrm{Nb}_{14} \mathrm{~W}_{3} \mathrm{O}_{44} \ldots \ldots \ldots \ldots \ldots \ldots$. . . . . . . . . . . . . . S11 


\section{Supplementary Methods}

Structure enumeration The space group of $\mathrm{Nb}_{14} \mathrm{~W}_{3} \mathrm{O}_{44}$ is reported as either $I \overline{4}$ or $I 4 / m[1,2]$. The $I 4 / m$ space group of $\mathrm{Nb}_{14} \mathrm{~W}_{3} \mathrm{O}_{44}$ requires a partial occupancy of the tetrahedral site and is therefore unsuitable for modelling purposes. In addition, the partial occupancy results in an unphysically small distance of less than $2 \AA$ between two neighbouring tetrahedral positions. Removal of the mirror plane perpendicular to $c$ (cf. Fig. 1, main text) allows full occupancy of the tetrahedral site and changes its multiplicity, and we therefore adopt $I \overline{4}$. The only difference between these two space group choices is the full or partial occupancy of the tetrahedral site. In the space groups $I \overline{4}$ and $I 4 / m$, it is impossible to keep the full symmetry and distribute three tungsten atoms over 17 sites within the primitive unit cell. Instead, for $\mathrm{Nb}_{14} \mathrm{~W}_{3} \mathrm{O}_{44}, 4$ configurations in space group $C 2$ and 168 configurations in space group $P 1$ were generated.

For $\mathrm{Nb}_{16} \mathrm{~W}_{5} \mathrm{O}_{55}$, the tetrahedral site was fixed to be occupied by tungsten, and the space group of the cation configurations was restricted to be $C 2$. The first constraint was imposed because tungsten preferentially occupies the tetrahedral site (see main text). The restriction on the space group choice is necessary to reduce the complexity of the problem. This leaves 10 symmetrically independent sites in the asymmetric unit (cf. Fig. 2, main text) over which two tungsten atoms are to be distributed, yielding $\frac{9 \times 10}{2}=45$ different cation configurations.

Level of theory All of the pristine phases studied in this work $\left(\mathrm{Nb}_{12} \mathrm{WO}_{33}, \mathrm{Nb}_{14} \mathrm{~W}_{3} \mathrm{O}_{44}\right.$, and $\left.\mathrm{Nb}_{16} \mathrm{~W}_{5} \mathrm{O}_{55}\right)$ are wide bandgap insulators featuring $d^{0}$ transition metals. Due to the absence of $d$ electrons whose self-interaction is to be corrected, the use of DFT $+U$ for these compounds is unjustified. On lithium insertion, the cations are reduced and states of mostly metal $d$ character are filled; in this case, the use of DFT $+U$ is more appropriate. Previous studies of reduced $d^{0}$ oxides (such as lithium insertion into $d^{0} \mathrm{TiO}_{2}[3,4]$ and reduced tungsten oxide phases $[5,6]$ ) use either GGA or GGA $+U$. Our previous work has shown that the use of self-interaction corrections can be necessary to produce the correct localisation behaviour in shear phases [7]. However, to evaluate thermodynamic properties, energies of pristine and lithiated phases have to be calculated with the same level of theory. As demonstrated in the main text, niobium-tungsten shear phases do not host strongly localised electrons and the differences between GGA and GGA $+U$ results are small.

\begin{tabular}{c|c|c} 
Element & Efficient & High accuracy \\
\hline \hline $\mathrm{Nb}$ & $3|1.9| 8|9| 10 \mid 40 \mathrm{U}: 50: 41: 42(\mathrm{qc}=5)$ & $3|1.5| 10|12| 13 \mid 40 \mathrm{U}: 50: 41: 42(\mathrm{qc}=6)$ \\
$\mathrm{W}$ & $3|2.3| 8|9| 10 \mid 50 \mathrm{U}: 60: 51: 52: 43(\mathrm{qc}=5)$ & $3|2.4| 9|10| 11 \mid 50 \mathrm{U}: 60: 51: 52: 43(\mathrm{qc}=6)$ \\
$\mathrm{O}$ & $2|1.7| 7|7| 9 \mid 20: 21(\mathrm{qc}=5)$ & $2|1.1| 15|18| 20 \mid 20: 21(\mathrm{qc}=7)$ \\
$\mathrm{Li}$ & $1|1.3| 8|9| 10 \mid 10 \mathrm{U}: 20(\mathrm{qc}=5)$ & $1|1.0| 14|16| 18 \mid 10 \mathrm{U}: 20(\mathrm{qc}=7)$
\end{tabular}

Table S1: CASTEP on-the-fly pseudopotentials used in this work. All pseudopotentials are from standard internal libraries of CASTEP. The first number indicates the angular momentum channel $l$ that is local. The second number is the core radius, $r_{c} . q_{c}$ is an optimisation parameter. Lower $q_{c}$ values result in smoother pseudopotentials, requiring smaller planewave kinetic energy cutoffs. The high accuracy pseudopotentials have a smaller core radius and are less optimised. 

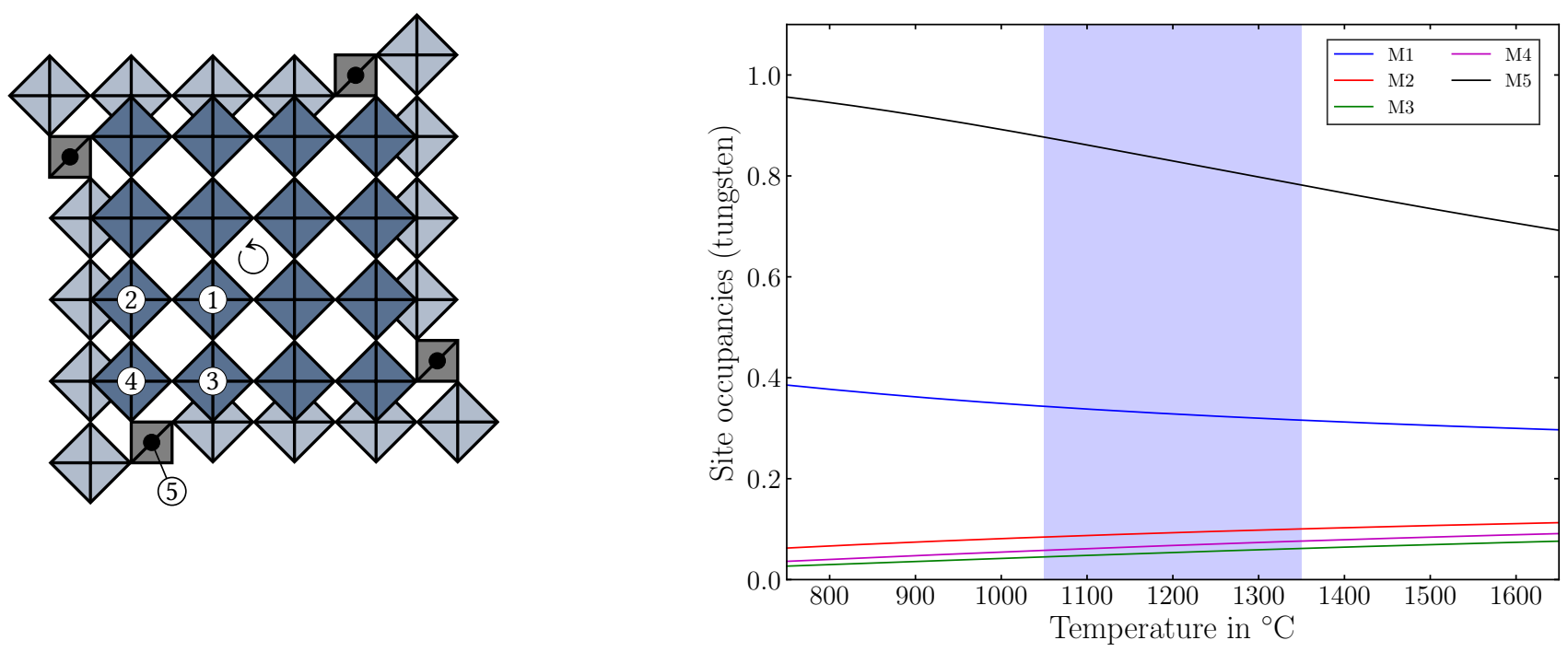

Figure S1: Occupancies of tungsten on transition metal sites in $\mathrm{Nb}_{14} \mathrm{~W}_{3} \mathrm{O}_{44}$ as a function of temperature. The region $1050-1350{ }^{\circ} \mathrm{C}$ is shaded in blue and corresponds to the range of synthesis and annealing temperatures.
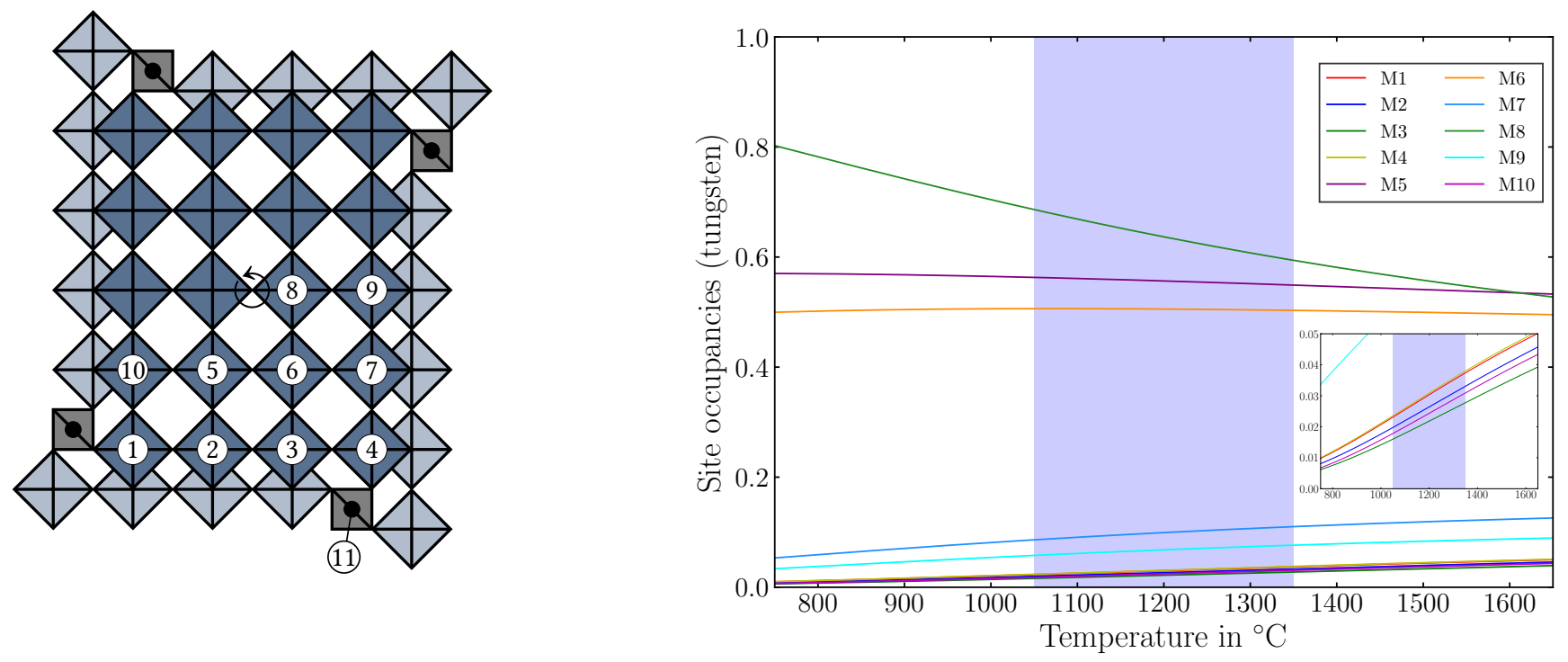

Figure S2: Occupancies of tungsten on transition metal sites in $\mathrm{Nb}_{16} \mathrm{~W}_{5} \mathrm{O}_{55}$ as a function of temperature. The region $1050-1350{ }^{\circ} \mathrm{C}$ is shaded in blue and corresponds to the range of synthesis and annealing temperatures. The M11 tetrahedral site is omitted as its occupancy is fixed to be one. The inset resolves site occupancies between 0.00 and 0.05 in the same temperature range. 


\begin{tabular}{|c|c|c|c|}
\hline \hline Site & DFT $\left(1050{ }^{\circ} \mathrm{C}\right)$ & DFT $\left(1200{ }^{\circ} \mathrm{C}\right)$ & DFT $\left(1350{ }^{\circ} \mathrm{C}\right)$ \\
\hline \hline M1 & 0.023 & 0.030 & 0.037 \\
M2 & 0.020 & 0.026 & 0.033 \\
M3 & 0.016 & 0.022 & 0.028 \\
M4 & 0.024 & 0.031 & 0.038 \\
M5 & 0.563 & 0.557 & 0.549 \\
M6 & 0.506 & 0.505 & 0.503 \\
M7 & 0.086 & 0.100 & 0.110 \\
M8 & 0.686 & 0.637 & 0.594 \\
M9 & 0.058 & 0.068 & 0.076 \\
M10 & 0.018 & 0.024 & 0.031 \\
M11 (tet. $)$ & 1.0 & 1.0 & 1.0 \\
\hline \hline
\end{tabular}

Table S2: Tungsten occupancies on cation sites in $\mathrm{Nb}_{16} \mathrm{~W}_{5} \mathrm{O}_{55}$. The occupancy of the tetrahedral M11 site was fixed to one during the enumeration. All sites except M11 have a multiplicity of two. Taking into account the degeneracies, the total $\mathrm{W}$ occupancy in a single block (cf. Fig. 2, main text) is five, as required. The synthesis temperature is reported as $1350{ }^{\circ} \mathrm{C}$ [8] or $1200{ }^{\circ} \mathrm{C}[9]$.

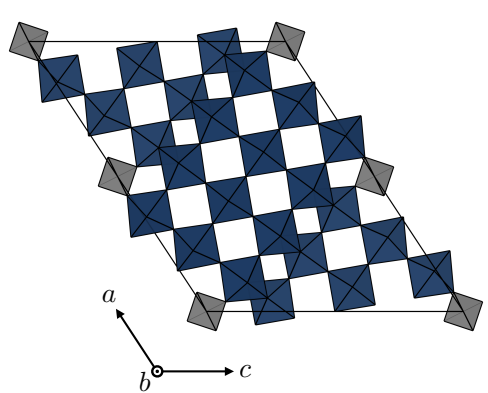

(a)

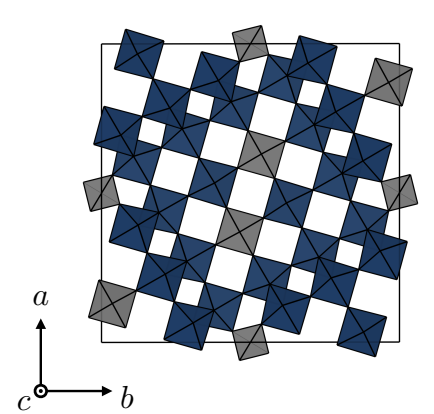

(b)

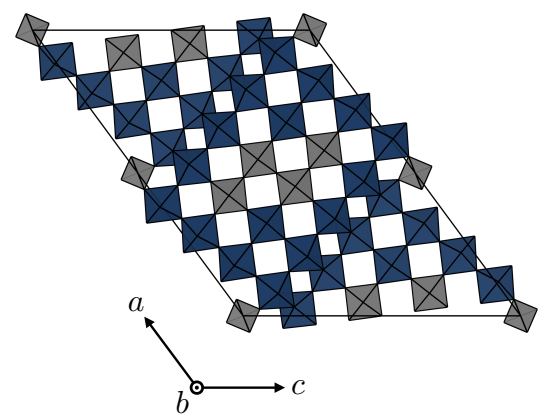

(c)

Figure S3: Lowest energy cation configurations of (a) $\mathrm{Nb}_{12} \mathrm{WO}_{33}$ (W on tetrahedral site), (b) $\mathrm{Nb}_{14} \mathrm{~W}_{3} \mathrm{O}_{44}$ (W on tetrahedral site, and two $\mathrm{M} 1$ positions), and (c) $\mathrm{Nb}_{16} \mathrm{~W}_{5} \mathrm{O}_{55}$ (W on tetrahedral, M8, and M5 sites). These have been used for all calculations presented in this work. 


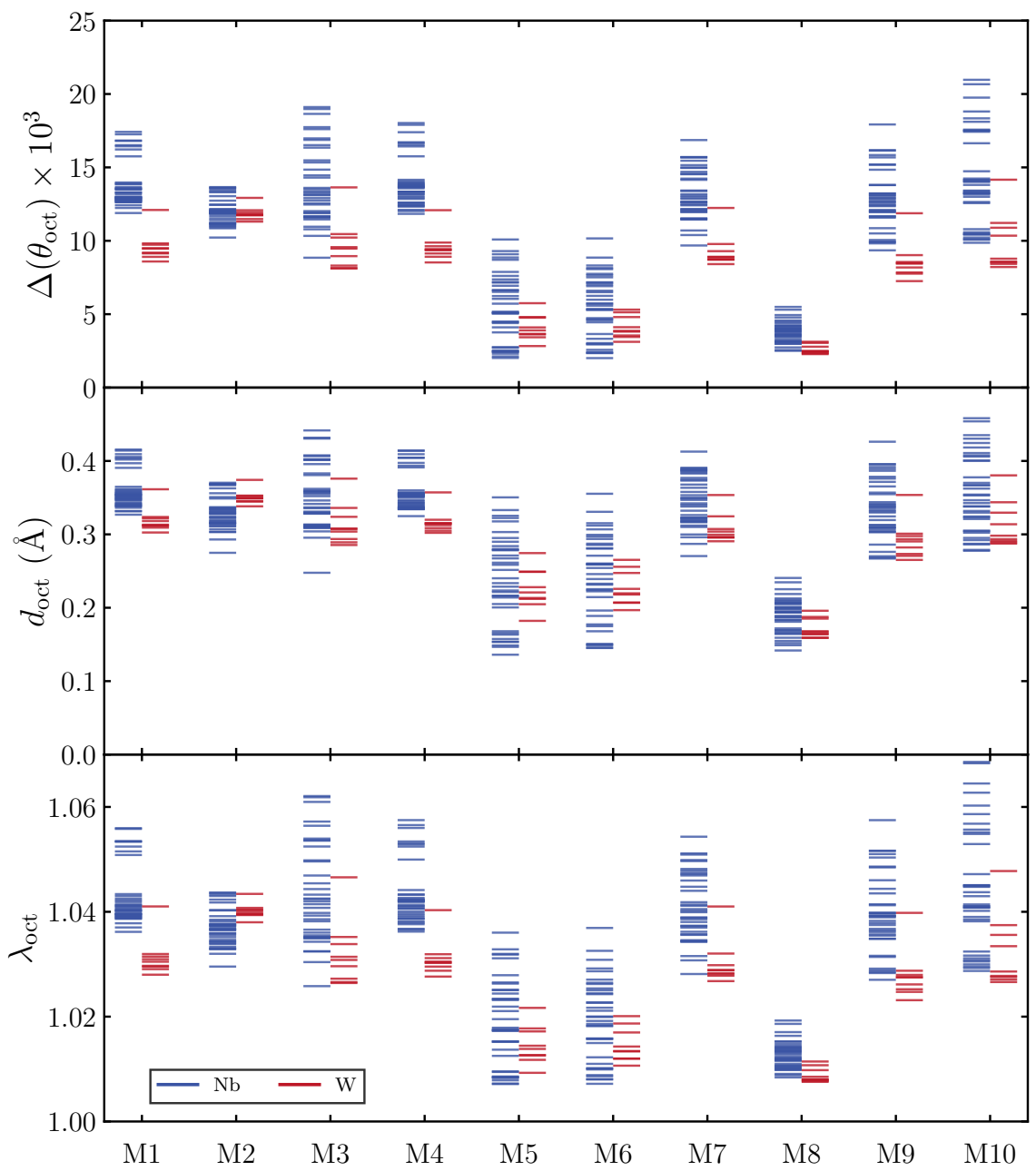

Figure S4: Local structure variability of $\mathrm{Nb}_{16} \mathrm{~W}_{5} \mathrm{O}_{55}$ cation configurations. Octahedral distortion measures for all sites M1-M10 and all 45 cation configurations. Block-central sites (M5, M6, and M8) show weaker distortions than the block-peripheral sites.

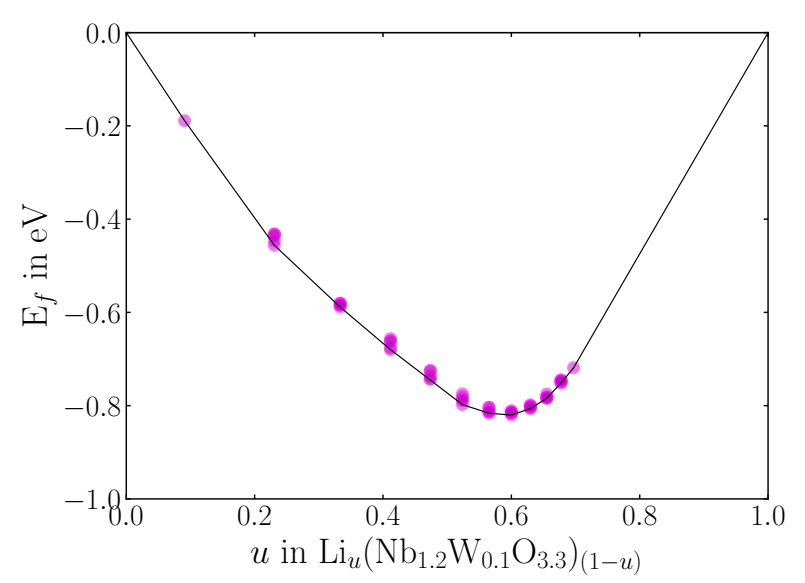

Figure S5: Convex hull of lowest energy $\mathrm{Li}_{x} \mathrm{Nb}_{12} \mathrm{WO}_{33}$ structures. At every stoichiometry, structures on the convex hull tieline or very close to it can be found.

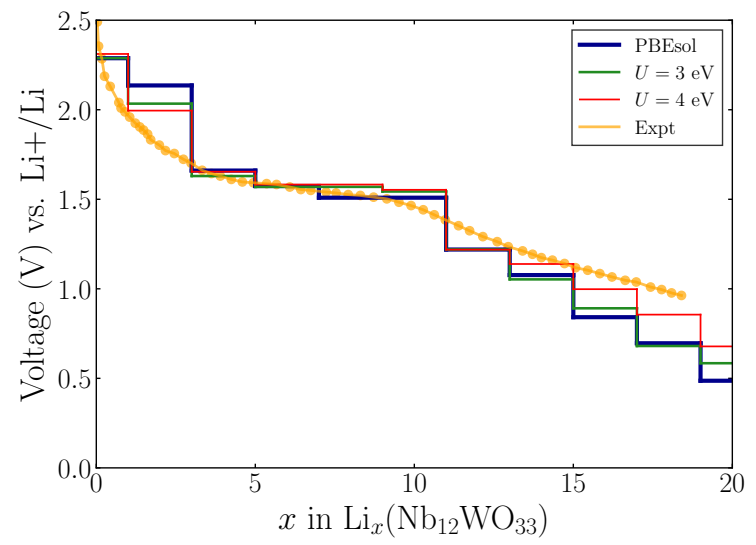

Figure S6: Comparison of DFT predicted voltage profiles to an experimental profile (Ref. [10]). The DFT predicted profiles have been shifted so that experimental and DFT predictions for the average insertion voltages agree. 

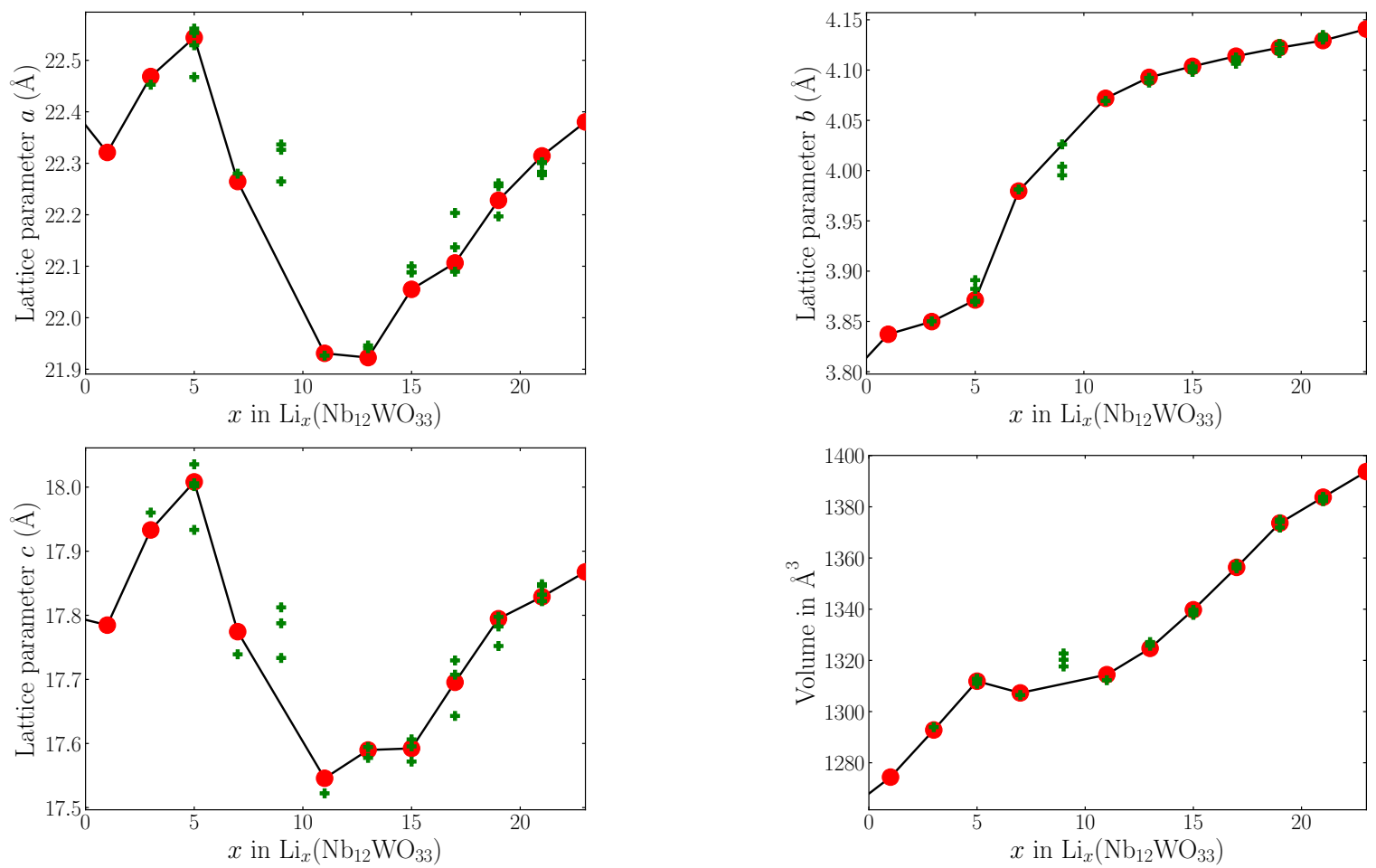

Figure S7: Lattice evolution of $\mathrm{Li}_{x} \mathrm{Nb}_{12} \mathrm{WO}_{33}$ including metastable phases less than $200 \mathrm{meV} /$ f.u. above the convex hull tieline. The red dots mark structures on the convex hull tieline, the green dots mark phases less than $200 \mathrm{meV} /$ f.u. above it. The overall trend of the lattice evolution described in the main text also holds when metastable phases are included. As $\mathrm{Li}_{x} \mathrm{Nb}_{12} \mathrm{WO}_{33}$ might form solid solutions experimentally, the fact that metastable phases show the same trend validates the use of single lithium configurations for modelling purposes.

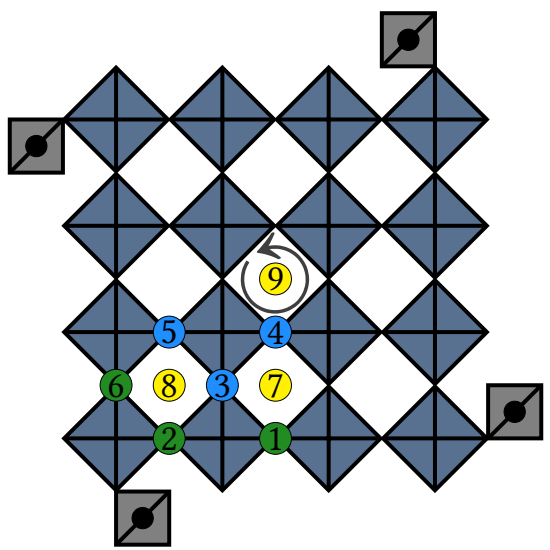

(a) $\mathrm{Nb}_{14} \mathrm{~W}_{3} \mathrm{O}_{44}$

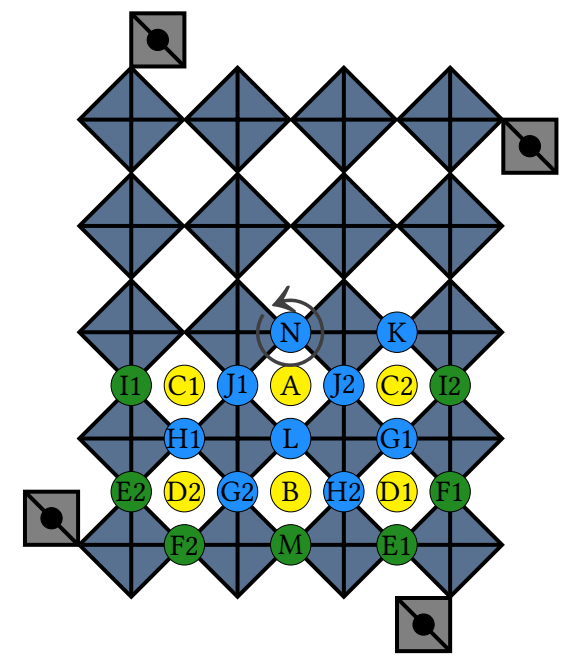

(b) $\mathrm{Nb}_{16} \mathrm{~W}_{5} \mathrm{O}_{55}$

Figure S8: Labelling convention for lithium positions in $\mathrm{Nb}_{14} \mathrm{~W}_{3} \mathrm{O}_{44}$ and $\mathrm{Nb}_{16} \mathrm{~W}_{5} \mathrm{O}_{55}$. Lithium sites in single blocks of (a) $\mathrm{Nb}_{14} \mathrm{~W}_{3} \mathrm{O}_{44}$, and (b) $\mathrm{Nb}_{16} \mathrm{~W}_{5} \mathrm{O}_{55}$ that were included in this study. Horizontal and vertical window positions (yellow and blue) are fourfold coordinated by oxygens, pocket positions (green) fivefold. Circling arrows mark the twofold $\left(\mathrm{Nb}_{16} \mathrm{~W}_{5} \mathrm{O}_{55}\right)$ or fourfold $\left(\mathrm{Nb}_{14} \mathrm{~W}_{3} \mathrm{O}_{44}\right)$ rotation axes of the parent crystal structures, which are perpendicular to the block plane. 


\begin{tabular}{|c|c|c|c|c|c|}
\hline Site in $\mathrm{Nb}_{12} \mathrm{WO}_{33}$ & $E_{f}$ & Site in $\mathrm{Nb}_{14} \mathrm{~W}_{3} \mathrm{O}_{44}$ & $E_{f}$ & Site in $\mathrm{Nb}_{16} \mathrm{~W}_{5} \mathrm{O}_{55}$ & $E_{f}$ \\
\hline $\bar{~} \overline{1}$ & $-2.10 \mathrm{eV}$ & $\bar{~} 1$ & $-2.19 \mathrm{eV}$ & $\overline{\mathrm{A}}$ & $-2.27 \mathrm{eV}$ \\
\hline 2 & $-2.06 \mathrm{eV}$ & 2 & $-2.05 \mathrm{eV}$ & B & $-2.35 \mathrm{eV}$ \\
\hline 3 & $-2.06 \mathrm{eV}$ & 3 & $-2.05 \mathrm{eV}$ & $\mathrm{C} 1$ & $-2.26 \mathrm{eV}$ \\
\hline 3 & $-2.06 \mathrm{eV}$ & 4 & $-2.14 \mathrm{eV}$ & $\mathrm{C} 2$ & $-2.33 \mathrm{eV}$ \\
\hline 4 & $-2.06 \mathrm{eV}$ & 5 & $-2.05 \mathrm{eV}$ & D1 & $-2.39 \mathrm{eV}$ \\
\hline 5 & $-2.07 \mathrm{eV}$ & 6 & $-2.13 \mathrm{eV}$ & D2 & $-2.30 \mathrm{eV}$ \\
\hline 6 & $-2.10 \mathrm{eV}$ & 7 & $-2.12 \mathrm{eV}$ & E1 & $-2.22 \mathrm{eV}$ \\
\hline 7 & $-2.09 \mathrm{eV}$ & 8 & $-2.16 \mathrm{eV}$ & E2 & $-2.28 \mathrm{eV}$ \\
\hline 8 & $-2.15 \mathrm{eV}$ & 9 & $-2.18 \mathrm{eV}$ & F1 & $-2.40 \mathrm{eV}$ \\
\hline 9 & $-2.11 \mathrm{eV}$ & & & F2 & $-2.36 \mathrm{eV}$ \\
\hline 10 & $-2.12 \mathrm{eV}$ & & & G1 & $-2.30 \mathrm{eV}$ \\
\hline 11 & $-2.06 \mathrm{eV}$ & & & G2 & $-2.08 \mathrm{eV}$ \\
\hline 12 & $-2.17 \mathrm{eV}$ & & & H1 & $-2.10 \mathrm{eV}$ \\
\hline & & & & $\mathrm{H} 2$ & $-2.28 \mathrm{eV}$ \\
\hline & & & & 11 & $-2.45 \mathrm{eV}$ \\
\hline & & & & $\begin{array}{l}12 \\
\mathrm{~J} 1\end{array}$ & $\begin{array}{l}-2.40 \mathrm{ev} \\
-2.25 \mathrm{eV}\end{array}$ \\
\hline & & & & $\begin{array}{l}\mathrm{J} 1 \\
\mathrm{~J} 2\end{array}$ & $\begin{array}{l}-2.39 \mathrm{eV} \\
\end{array}$ \\
\hline & & & & $\mathrm{K}$ & $-1.85 \mathrm{eV}$ \\
\hline & & & & $\mathrm{L}$ & $-2.41 \mathrm{eV}$ \\
\hline & & & & M & $-2.41 \mathrm{eV}$ \\
\hline & & & & $\mathrm{N}$ & $-2.09 \mathrm{eV}$ \\
\hline
\end{tabular}

Table S3: Lithium site energies in $\mathrm{Nb}_{12} \mathrm{WO}_{33}, \mathrm{Nb}_{14} \mathrm{~W}_{3} \mathrm{O}_{44}$, and $\mathrm{Nb}_{16} \mathrm{~W}_{5} \mathrm{O}_{55}$. The $E_{f}$ values for $\mathrm{Nb}_{12} \mathrm{WO}_{33}$ were obtained as described in the main text. The $E_{f}$ values for positions 1-8 in $\mathrm{Nb}_{14} \mathrm{~W}_{3} \mathrm{O}_{44}$ and $\mathrm{A}-\mathrm{M}$ in $\mathrm{Nb}_{16} \mathrm{~W}_{5} \mathrm{O}_{55}$ were obtained by placing two lithium ions in the primitive cell under constraints of the crystal symmetry. For the special positions 9 and N, a single lithium ion was used.

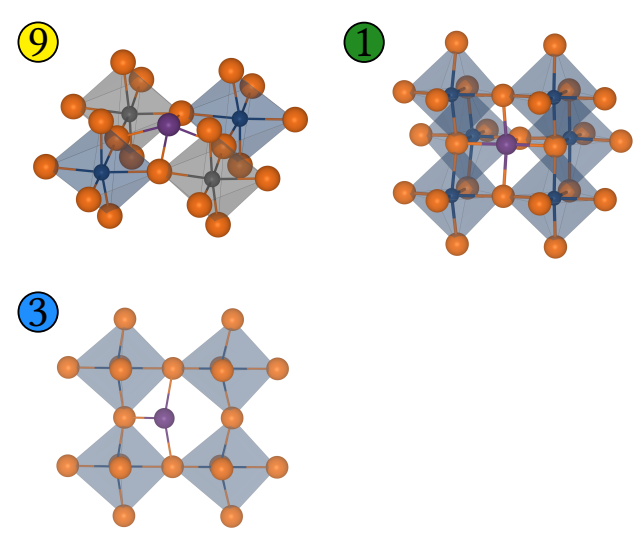

(a) $\mathrm{Nb}_{14} \mathrm{~W}_{3} \mathrm{O}_{44}$
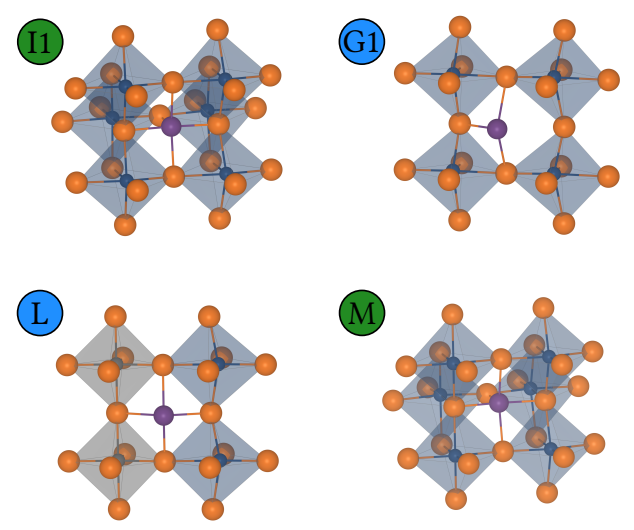

(b) $\mathrm{Nb}_{16} \mathrm{~W}_{5} \mathrm{O}_{55}$

Figure S9: Examples of local structure of lithium sites in (a) $\mathrm{Nb}_{14} \mathrm{~W}_{3} \mathrm{O}_{44}$ and (b) $\mathrm{Nb}_{16} \mathrm{~W}_{5} \mathrm{O}_{55}$. Note the strong similarity between all three niobium-tungsten oxides (cf. Fig. 4, main text). 


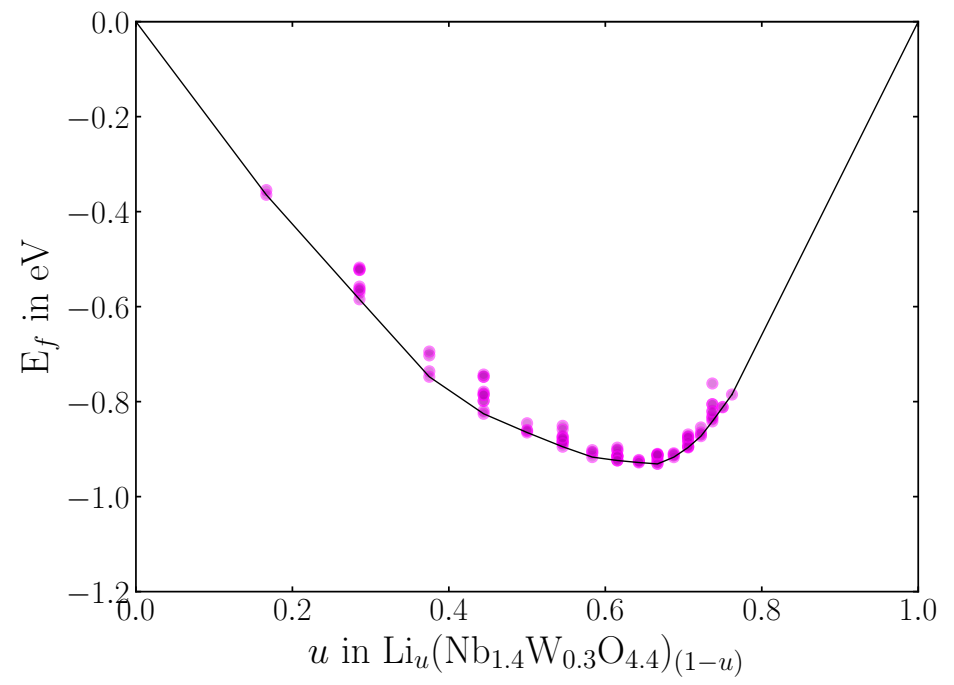

Figure S10: Convex hull of $\mathrm{Li}_{x} \mathrm{Nb}_{14} \mathrm{~W}_{3} \mathrm{O}_{44}$. At every stoichiometry, a structure on the convex hull tieline can be found.
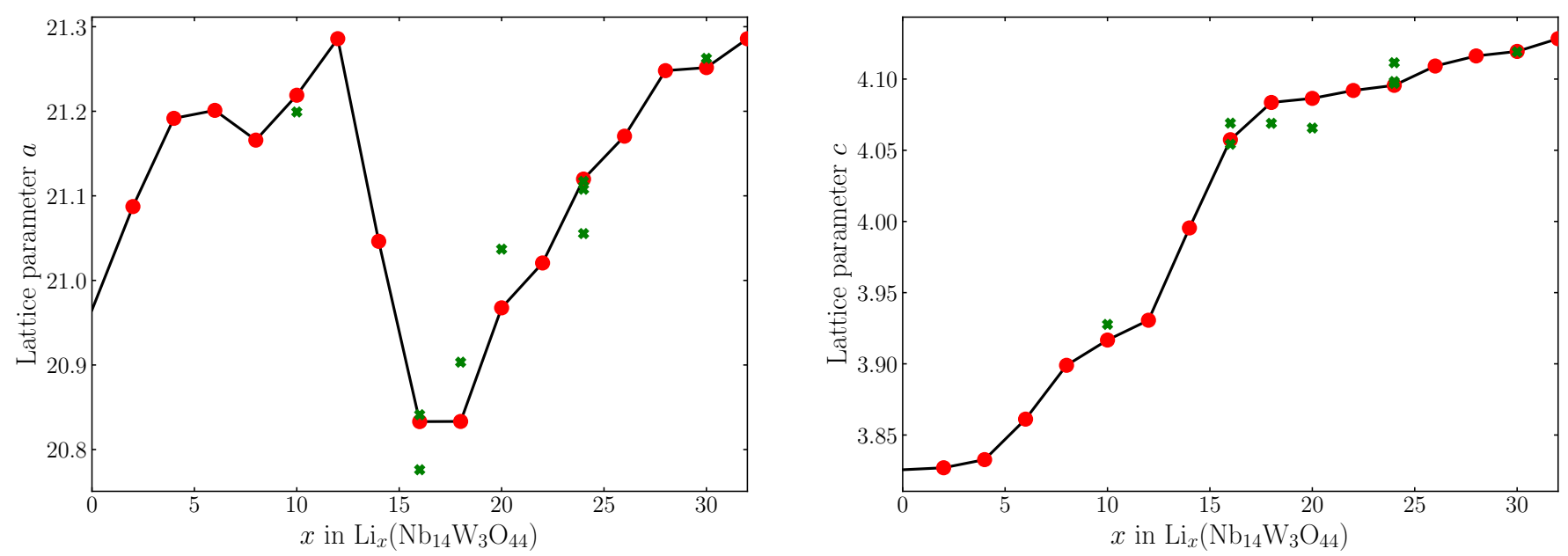

Figure S11: Lattice evolution of $\mathrm{Li}_{x} \mathrm{Nb}_{14} \mathrm{~W}_{3} \mathrm{O}_{44}$ including metastable phases that are less than 100 $\mathrm{meV} /$ f.u. above the convex hull tieline. Structures above the convex hull tieline are marked by green dots. As $\mathrm{Li}_{x} \mathrm{Nb}_{14} \mathrm{~W}_{3} \mathrm{O}_{44}$ might form solid solutions experimentally, the fact that metastable phases show the same trend validates the use of single lithium configurations for modelling purposes. 


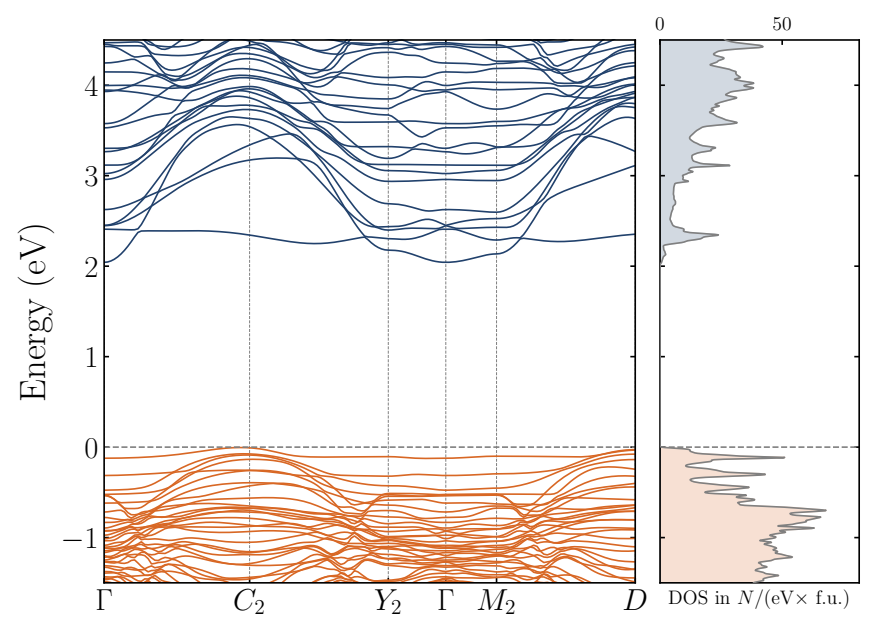

(a) $\mathrm{Nb}_{12} \mathrm{WO}_{33}$

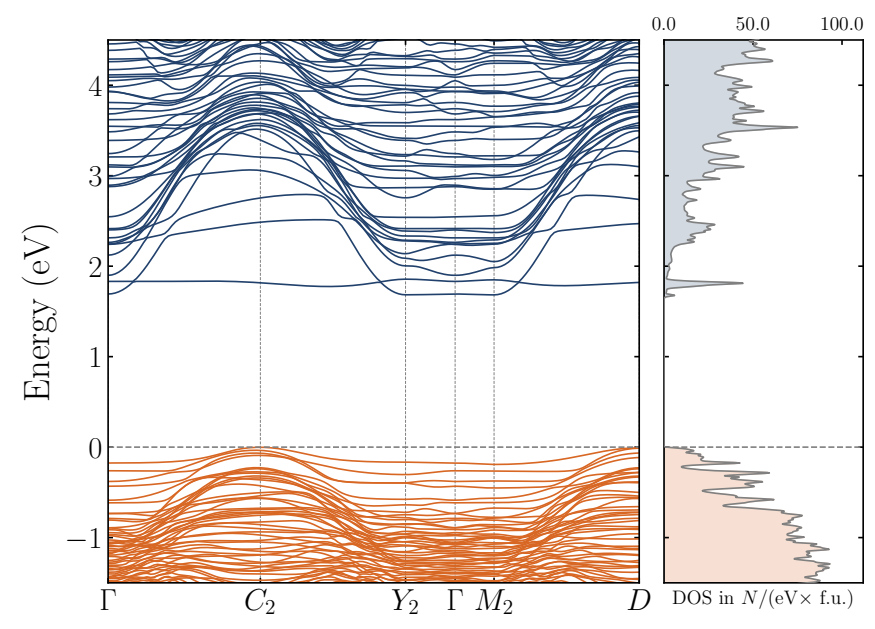

(b) $\mathrm{Nb}_{16} \mathrm{~W}_{5} \mathrm{O}_{55}$

Figure S12: Bandstructures and electronic densities of states of (a) $\mathrm{Nb}_{12} \mathrm{WO}_{33}$ and (b) $\mathrm{Nb}_{16} \mathrm{~W}_{5} \mathrm{O}_{55}$. The bandstructure path segments are the same as for $\mathrm{Nb}_{14} \mathrm{~W}_{3} \mathrm{O}_{44}$ (main text). Oxygen $2 p$ dominated valence band is coloured in orange, while the $\mathrm{Nb} 4 d / \mathrm{W} 5 d$ conduction band is shown in blue. Both flat and dispersive conduction bands are present. The long band structure path segments involve changes in wavevector $\mathbf{k}$ along the direction reciprocal to the lattice parameter perpendicular to the block plane $\left(\mathbf{b}^{*}\right)$. The Fermi level (dashed line) sits on top of the valence band.

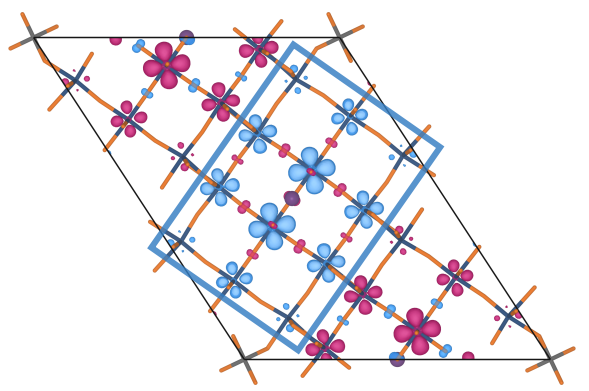

(a) $\mathrm{Li}_{1} \mathrm{Nb}_{12} \mathrm{WO}_{33}$

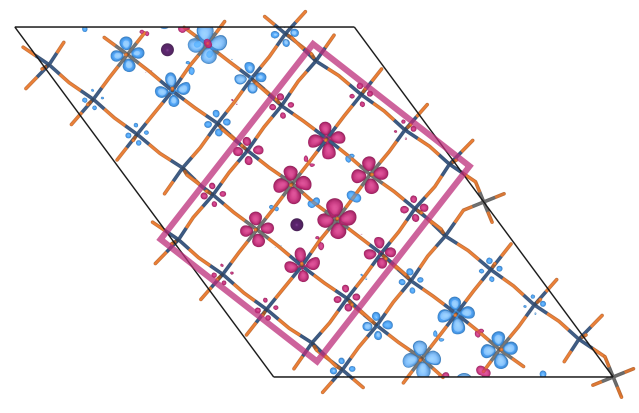

(b) $\mathrm{Li}_{1} \mathrm{Nb}_{16} \mathrm{~W}_{5} \mathrm{O}_{55}$

Figure S13: Spin densities of (a) $\mathrm{Li}_{1} \mathrm{Nb}_{12} \mathrm{WO}_{33}$ and (b) $\mathrm{Li}_{1} \mathrm{Nb}_{16} \mathrm{~W}_{5} \mathrm{O}_{55}$ for antiferromagnetic spin arrangements between blocks. Through lithium insertion, a single electron per block has been doped into the structure. The $3 \times 4\left(\mathrm{Nb}_{12} \mathrm{WO}_{33}\right)$ and $4 \times 5\left(\mathrm{Nb}_{16} \mathrm{~W}_{5} \mathrm{O}_{55}\right)$ blocks are outlined by rectangles. 


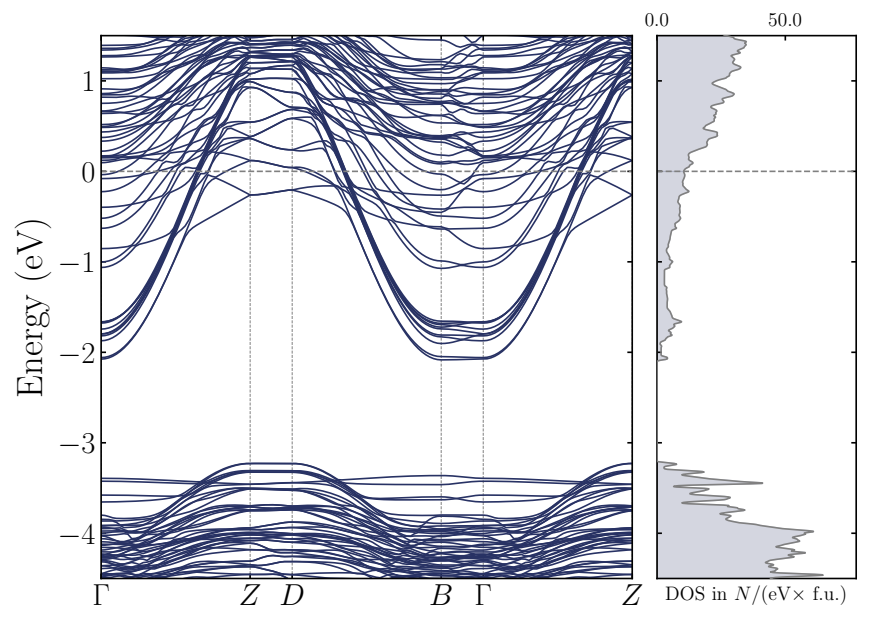

(a) $\mathrm{Li}_{13} \mathrm{Nb}_{12} \mathrm{WO}_{33}$

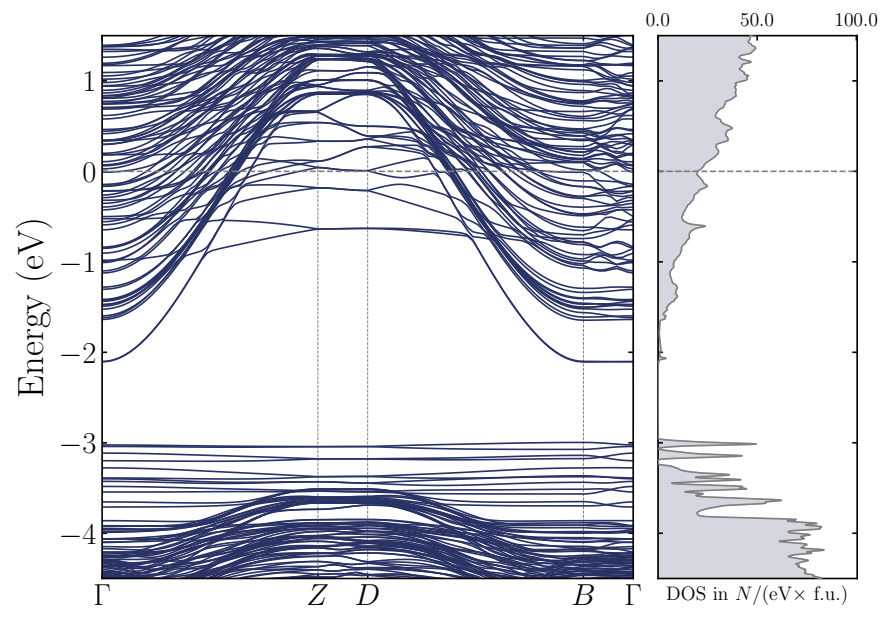

(b) $\mathrm{Li}_{21} \mathrm{Nb}_{16} \mathrm{~W}_{5} \mathrm{O}_{55}$

Figure S14: Bandstructures and electronic densities of states of (a) $\mathrm{Li}_{13} \mathrm{Nb}_{12} \mathrm{WO}_{33}$ and (b) $\mathrm{Li}_{21} \mathrm{Nb}_{16} \mathrm{~W}_{5} \mathrm{O}_{55}$ (1 Li/TM, full lithiation). The dispersive bands and finite density of states at the Fermi level (dashed line) suggest metallicity and good electronic conductivity of the materials. The calculations were performed for the lowest energy $\mathrm{Li}_{13} \mathrm{Nb}_{12} \mathrm{WO}_{33}$ structure found by enumeration, and the $\mathrm{Li}_{21} \mathrm{Nb}_{16} \mathrm{~W}_{5} \mathrm{O}_{55}$ structure model described in the text.

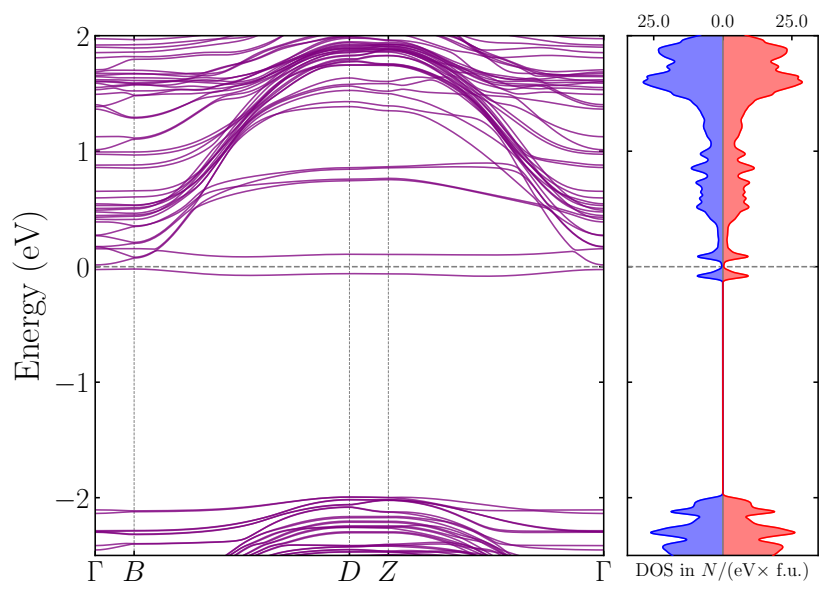

(a) PBEsol

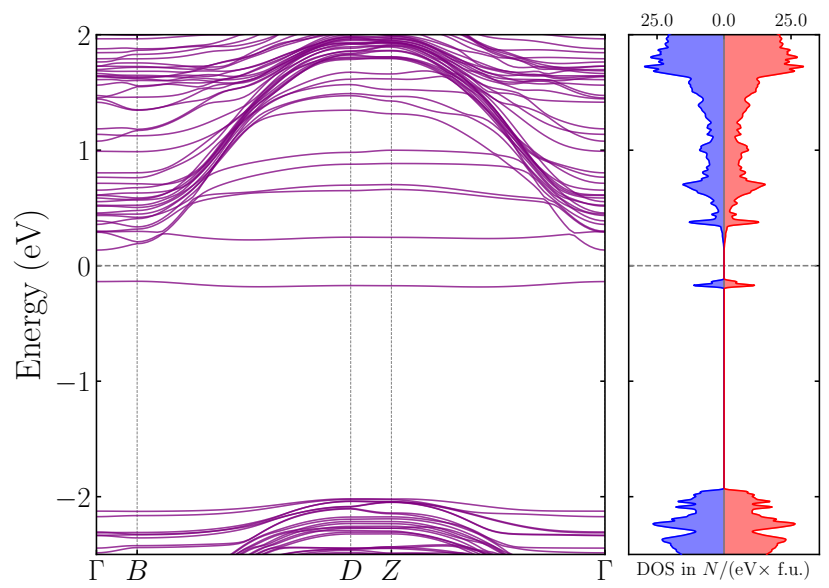

(b) PBEsol $+U$

Figure S15: Bandstructures and electronic densities of states of $\mathrm{Li}_{1} \mathrm{Nb}_{14} \mathrm{~W}_{3} \mathrm{O}_{44}$ computed with (a) PBEsol and (b) PBEsol $+U(U=4.0 \mathrm{eV})$. The gap between the occupied flat bands and the remaining conduction states is present in both. The bandstructure calculations were performed in the conventional unit cells (rather than the primitive) to allow antiferromagnetic spin arrangements between blocks, and the high symmetry points are therefore labelled differently. 


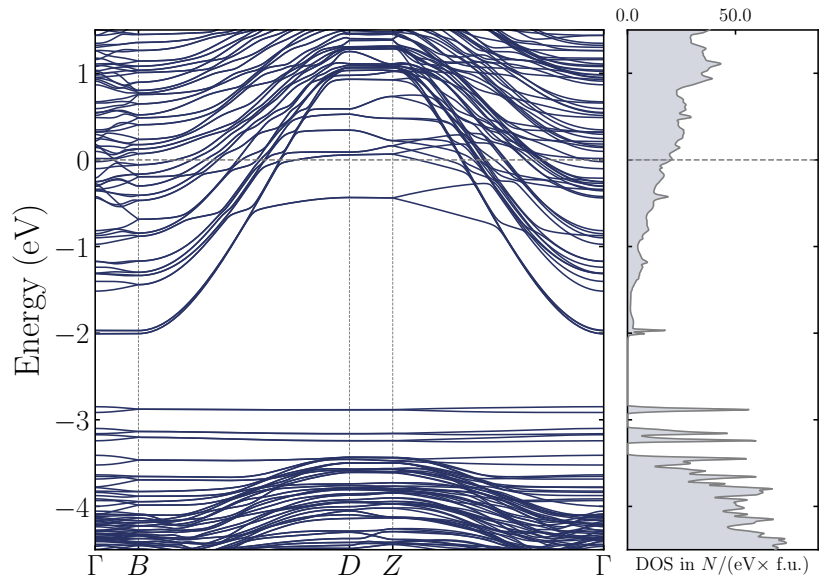

(a) PBEsol

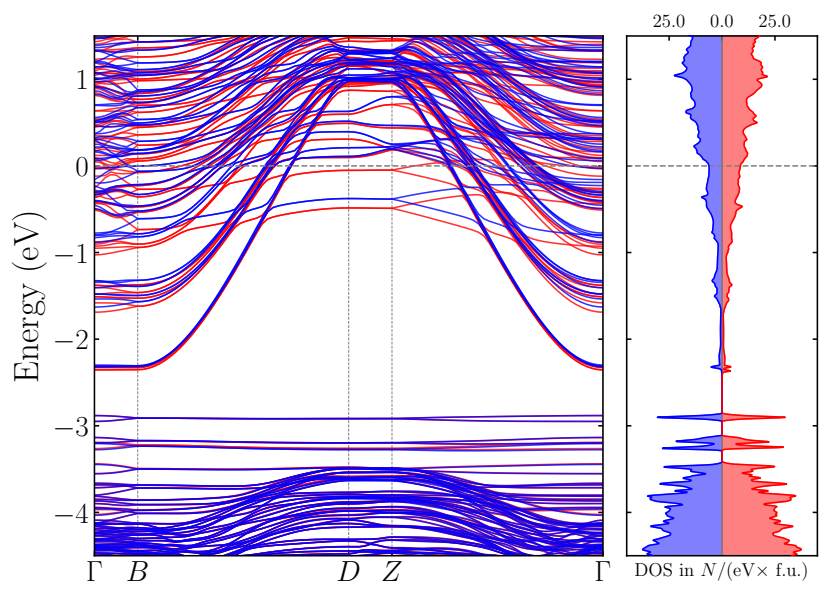

(b) PBEsol+U

Figure S16: Electronic structure of $\mathrm{Li}_{16} \mathrm{Nb}_{14} \mathrm{~W}_{3} \mathrm{O}_{44}$. At the GGA level (a) no spin polarisation is observed. Inclusion of a $U$ value on the metal $d$ orbitals (b) does not lead to the opening of a bandgap. The multitude of strongly dispersive bands suggests a good electronic conductivity of the material. Red and blue correspond to spin up and down bands.

\section{References}

[1] R. S. Roth and A. D. Wadsley. Multiple phase formation in the binary system $\mathrm{Nb}_{2} \mathrm{O}_{5}-\mathrm{WO}_{3}$. III. The structures of the tetragonal phases $\mathrm{W}_{3} \mathrm{Nb}_{14} \mathrm{O}_{44}$ and $\mathrm{W}_{8} \mathrm{Nb}_{18} \mathrm{O}_{69}$. Acta Crystallographica, 19(1):38-42, July 1965.

[2] A. K. Cheetham and N. C. Allen. Cation distribution in the complex oxide, $\mathrm{W}_{3} \mathrm{Nb}_{14} \mathrm{O}_{44}$; a time-of-flight neutron diffraction study. Journal of the Chemical Society, Chemical Communications, 0(22):1370-1372, January 1983.

[3] Anna A. Belak, Yizhou Wang, and Anton Van der Ven. Kinetics of Anatase Electrodes: The Role of Ordering, Anisotropy, and Shape Memory Effects. Chemistry of Materials, 24(15):2894-2898, August 2012.

[4] Andrew S. Dalton, Anna A. Belak, and Anton Van der Ven. Thermodynamics of Lithium in $\mathrm{TiO}_{2}$ (B) from First Principles. Chemistry of Materials, 24(9):1568-1574, May 2012.

[5] Joseph T. Schick, Lai Jiang, Diomedes Saldana-Greco, and Andrew M. Rappe. Coupling between octahedral rotations and local polar displacements in $\mathrm{WO}_{3} / \mathrm{ReO}_{3}$ superlattices. Physical Review B, 89(19), May 2014.

[6] Zhiguo Wang, Yang He, Meng Gu, Yingge Du, Scott X. Mao, and Chongmin Wang. Electron Transfer Governed Crystal Transformation of Tungsten Trioxide upon Li Ions Intercalation. ACS Applied Materials \& Interfaces, 8(37):24567-24572, September 2016.

[7] Can P. Koçer, Kent J. Griffith, Clare P. Grey, and Andrew J. Morris. First-principles study of localized and delocalized electronic states in crystallographic shear phases of niobium oxide. Physical Review B, 99(7):075151, February 2019.

[8] R. S. Roth and A. D. Wadsley. Multiple phase formation in the binary system $\mathrm{Nb}_{2} \mathrm{O}_{5}-\mathrm{WO}_{3}$. I. Preparation and identification of phases. Acta Crystallographica, 19(1):26-32, July 1965.

[9] Kent J. Griffith, Kamila M. Wiaderek, Giannantonio Cibin, Lauren E. Marbella, and Clare P. Grey. Niobium tungsten oxides for high-rate lithium-ion energy storage. Nature, 559(7715):556-563, July 2018.

[10] Lei Yan, Hua Lan, Haoxiang Yu, Shangshu Qian, Xing Cheng, Nengbing Long, Ruifeng Zhang, Miao Shui, and Jie Shu. Electrospun $\mathrm{WNb}_{12} \mathrm{O}_{33}$ nanowires: Superior lithium storage capability and their working mechanism. Journal of Materials Chemistry A, 5(19):8972-8980, May 2017. 